\title{
The influence of acute hypoxic exposure on isokinetic muscle force production
}

\author{
Rafael Kenji Ivamoto ${ }^{1}$, Fernanda Patti Nakamoto ${ }^{1}$, Rodrigo Luiz Vancini ${ }^{2}$, Ana Amélia Benedito-Silva ${ }^{3}$, \\ Claudio Andre Barbosa de Lira ${ }^{4 \dagger}$ and Marília dos Santos Andrade ${ }^{1 *+}$
}

\begin{abstract}
To investigated whether an acute hypoxic stimulus affects muscle strength development assessed by isokinetic dynamometry during maximal knee extension. A total of 15 healthy young men participated in this study $(61.9 \pm 6.1 \mathrm{~kg}$; $1.72 \pm 0.08 \mathrm{~m} ; 20.9 \pm 2.6$ years). We evaluated knee extension and flexion isokinetic dynamometer performance in normoxic and hypoxic conditions. The analyzed parameters, for concentric contraction, were peak torque and total work measured at 1.05 and $5.23 \mathrm{rad} / \mathrm{s}$; and fatigue index measured at $5.23 \mathrm{rad} / \mathrm{s}$. During isokinetic testing, heart rate and oxygen saturation $\left(\mathrm{SpO}_{2}\right)$ were monitored. Hypoxic conditions (3,600 $\mathrm{m}$ ) were simulated, via a mixing chamber, with the dilution being constantly controlled by a $\mathrm{PO}_{2}$ probe. Test reproducibility results (test-retest) for all isokinetic knee parameters were classified as moderate to almost perfect (ICC $=0.694$ to 0.932 ). $\mathrm{SpO}_{2}$ was $88.4 \pm 3.4 \%$ in the hypoxic condition and $97.1 \pm 0.7 \%$ in the normoxic condition ( $p=0.000$, effect size $=0.87$ ). Heart rate was not significantly different between normoxic and hypoxic conditions at the end of the test. There were no significant differences in isokinetic variables evaluated for the extensor and flexor muscles at concentric contraction between the normoxic and hypoxic conditions. Our findings indicate that reduced arterial oxygenation per se has no effect on the muscular isokinetic strength of the knee extensors.
\end{abstract}

Keywords: Normoxia; Isokinetic dynamometry; Knee muscle strength; Oxygen saturation

\section{Introduction}

It is well known that a hypoxemic stimulus produces a significant reduction in aerobic performance (Wehrlin and Hallen 2006), however less is known about the effects of hypoxemic exposure on muscle strength development. During chronic exposure to hypobaric hypoxemia (real or simulated high altitude), several authors reported no change in maximal voluntary contraction - MVC (Garner et al. 1990; Fulco et al. 1994; Orizio et al. 1994; Caquelard et al. 2000). By contrast, during acute hypoxemia (inhalation of 10 to $12 \%$ oxygen gas mixtures) the results are contradictory since several authors noted a decrease in MVC (Eiken and Tesch 1984; Badier et al. 1994; Bendahan et al. 1998). This has been attributed to alterations in muscle energetics, impaired neuromuscular transmission, and/or changes in the central drive during contractions.

\footnotetext{
* Correspondence: marillia1707@gmail.com

${ }^{\dagger}$ Equal contributors

'Departamento de Fisiologia, Universidade Federal de São Paulo (UNIFESP), Rua Botucatu, 862, $5^{\circ}$ andar, Ed. Ciências Biomédicas, CEP 04023-062 São Paulo, SP, Brazil

Full list of author information is available at the end of the article
}

Dousset et al. (2001) showed a decrease in MVC and a reduction of central drive to muscle fibers in hypoxic conditions. Also, a reduction in the recruitment of slowtwitch motor units (highly oxygen-dependent fibers) was observed. These data corroborate the Central Governor Theory proposed by Hill, Long and Lupton between 1923 and 1925 which is supported by Noakes et al. (2001). These authors proposed that peripheral fatigue occurs only after the onset of myocardial fatigue (it could also be due to respiratory muscle or central nervous system fatigue) that constantly send, by afferent fibers information to brain (the central governor) about peripheral metabolic status. If there is any threat of ischemia or hypoxia, the central governor immediately reduces efferent neural activation to the exercised muscles, thus decreasing the muscle mass that can be recruited (Noakes et al. 2001).

It is clear that the effects of acute hypoxia on muscular strength are a topic of extensive debate. Thus, the purpose of this study was to investigate whether an acute hypoxic stimulus affects muscle strength development assessed by

\section{实}


isokinetic dynamometry during maximal isokinetic knee extension and flexion. Obtaining these responses is valuable for guidance training in hypoxic conditions.

\section{Methods \\ Participants}

A total of 15 young men volunteered to participate in this study (body mass: $61.9 \pm 6.1 \mathrm{~kg}$; height: $1.72 \pm 0.08 \mathrm{~m}$; age: $20.9 \pm 2.6$ years, data are presented as mean \pm standard deviation). Participants were recruited among students of the Federal University of São Paulo (São Paulo, Brazil). The participants were sedentary or recreationally active and asymptomatic. The inclusion criteria were: not having participated in resistance training for at least a year before the study; able to perform physical exercise; not having been exposed to altitudes above $3000 \mathrm{~m}$ at least one month before study; no chronic disease; and not currently smoking or using drugs/ergogenic aids that could affect muscular function. After a clear explanation of the procedures, including the risks and benefits of participation, written consent was obtained. All experimental procedures were approved by the University Human Research Ethics Committee and they conformed to the principles outlined in the Declaration of Helsinki. All participants were highly motivated to participate in the study. They were requested to refrain from strenuous workouts the day before the experimental procedures.

\section{Study design}

The study was organized in three successive phases: (1) familiarization with isokinetic dynamometer and isokinetic assessment in normoxic (2) or hypoxic condition (3). The order of phases (2) and (3) was randomized. These phases were separated by at least 1 day up to a maximum of 3 days. We correlated the isokinetic assessment results performed in phase 1 with the normoxic condition assessment results in order to verify the reproducibility of the tests. The hypoxic condition evaluation results were compared with the normoxic condition results in order to compare the effect of hypoxia on muscle strength development. Before isokinetic assessment, participants were submitted to 10 minutes under hypoxic stimulus.

\section{Isokinetic procedures}

Before isokinetic assessment, a 5 minute warm-up was performed on a cycle ergometer (Schwinn Air-Dyne ${ }^{\circ}$, Nautilus Inc, USA) at a resistance level of $50 \mathrm{~W}$. Following the warm-up period, subjects were placed in the isokinetic dynamometer (Cybex 6000, Ronkonkowa, New York, USA) to perform concentric strength exercise bouts for dominant lower limbs. Limb dominance was determined by asking the subjects which limb they preferred to use when kicking a ball. Subjects assumed a seated position on the isokinetic dynamometer with their hips flexed at approximately 85 degrees. Standard stabilization strapping was placed across the trunk and waist. The distal femur of the limb was also stabilized during the tests to minimize additional movement and to ensure identical conditions for all participants. The dynamometer axis was visually aligned with lateral femoral condyle while the knees were flexed at 90 degrees. The length of the lever arm was individually determined by the length of each individual's lower leg, and the resistance pad was placed proximal to the medial malleolus. Following the direct measurement of the lower limb mass lever system at 30 degrees of knee extension, gravity correction procedures were applied according to the manufacturer's specifications to reduce the risk of inaccurate data.

As part of the familiarization process, the participants were given standard verbal instructions regarding the procedures and were allowed several sub-maximal practice attempts for each angular velocity used (1.05 and $5.23 \mathrm{rad} / \mathrm{s})$. The subjects were then tested with 5 repetitions at $1.05 \mathrm{rad} / \mathrm{s}$ and 30 repetitions at $5.23 \mathrm{rad} / \mathrm{s}$ performed at concentric contraction, and the results were stored for analysis. All subjects received a 60 second rest period between sets to prevent fatigue build-up. Verbal commands were given by the examiner before each test to ensure maximal effort, and visual feedback of the recorded torque was provided during the test. All subjects were tested by the same examiner who was trained and experienced in the use of isokinetic testing devices.

The evaluated parameters were: 1) hamstring and quadriceps isokinetic peak torque at 1.05 and $5.23 \mathrm{rad} / \mathrm{s}$ in Newton.m (Nm); 2) hamstring and quadriceps muscles total work in Joules (J) measured at 1.05 and $5.23 \mathrm{rad} / \mathrm{s}$; and 3) fatigue index as a percentage measured at $5.23 \mathrm{rad} / \mathrm{s}$. All obtained values correspond to concentric contractions. The fatigue index was calculated by dividing the minimum torque values by the maximum torque values at the same angular speed. In order to verify whether the participant actually performed maximal voluntary contraction in all repetitions of the test, we evaluated the variation coefficient provided by the equipment software (standard deviation expressed as a percentage of the mean). The maximum variation accepted was $10 \%$. The dynamometer was monthly calibrated according to the manufacturer's specifications and was checked prior to each individual test.

During isokinetic testing, heart rate (HR) and oxygen saturation $\left(\mathrm{SpO}_{2}\right)$ were monitored. Heart rate registers (5 seconds average HR value) were monitored by a commercially available system (S810i, Polar Electronics, Kempele, Oulu) and $\mathrm{SpO}_{2}$ was monitored every minute by a pulse oximeter (Pulse Oximeter OctiveTech 300CSE ${ }^{\circ}$, Atlanta, USA).

\section{Altitude simulation}

Normobaric hypoxic conditions corresponding to an altitude of 3,600 m (fraction of inspired oxygen - $\mathrm{FIO}_{2}=13 \%$ ) 
were simulated, according to Kon et al. (2010), by diluting ambient air with nitrogen (Air Liquide, São Paulo, Brazil) via a mixing chamber, with the dilution being constantly controlled by an oxygen partial pressure $\left(\mathrm{PO}_{2}\right)$ probe (AltiTrainer200, Sport and Medical Technology, Geneva, Switzerland). This device allows the inspired $\mathrm{PO}_{2}$ to be set at a predetermined value to simulate altitude. Participants were attached to the device through a mask. The precision of the $\mathrm{PO}_{2}$ is of \pm 0.82 Torr. The device was calibrated weekly according to the manufacturer's instructions. The hypoxic stimulus was initiated 10 minutes prior to isokinetic testing.

During the normobaric condition, participants underwent the same procedure as for the hypoxic condition, namely that they were coupled to the device through a mask, but instead breathed room air $\left(\mathrm{FIO}_{2}=20.93 \%\right)$.

\section{Statistical analysis}

A clinically important and relevant difference in peak torque value has been suggested to be $15 \%$ (Croisier et al. 2008, Yeung et al. 2009). A sample size calculation on the peak torque, using a logistic rank survival power analysis, showed that fifteen subjects are needed to detect a clinically relevant difference with $80 \%$ power and a significance level of $5 \%$.

All variables presented normal distributions $(\mathrm{p}>0.05)$ according to Kolmogorov-Smirnov tests. Intraclass correlation coefficients' (ICCs) were calculated to determine the test-retest reliability. The ICCs were interpreted as follows: 0.90-0.99, almost perfect agreement; 0.70-0.89, strong agreement; $0.50-0.69$, moderate agreement; 0.3 0.49 , fair agreement; 0.0-0.29, poor agreement (Munro et al. 1986). Subsequently, the differences between the two conditions (normoxia versus hypoxia) were analyzed with a paired Student- $t$ test. The level of significance was $\mathrm{p}<0.05$. Data are showed as mean \pm standard deviation (SD). All statistical analyses were performed with Statistica, version 7.0 (Statsoft Inc, Tulsa, Oklahoma, USA). In addition, the measures of the effect size for changes in outcome were calculated by dividing the mean difference by the standard deviation (SD) of the normobaric hypoxic conditions measurement. Calculating effect sizes, the magnitude of any change was judged according to the following criteria: ES $=0.2$ considered a "small" effect size; 0.5 represented a "medium" effect size; and 0.8 a "large" effect size (Cohen 1988).

\section{Results}

The test-retest ICCs (test reproducibility results) for all measurements were classified as moderate to almost perfect as following: Extensor muscles peak torque at $5.23 \mathrm{rad} / \mathrm{s}-\mathrm{ICC}=0.927$, almost perfect agreement; Extensor muscles peak torque at $1.05 \mathrm{rad} / \mathrm{s}-\mathrm{ICC}=0.866$, strong agreement; Flexor muscles peak torque at
$5.23 \mathrm{rad} / \mathrm{s}-\mathrm{ICC}=0.800$, strong agreement; Flexor muscles peak torque $1.05 \mathrm{rad} / \mathrm{s}-\mathrm{ICC}=0.735$, strong agreement; Extensor muscles total work at $5.23 \mathrm{rad} / \mathrm{s}$ ICC $=0.694$, moderate agreement; Flexor muscles total work at $5.23 \mathrm{rad} / \mathrm{s}-\mathrm{ICC}=0.821$, strong agreement; Extensor muscles fatigue index (\%) - ICC $=0.932$, almost perfect agreement; and Flexor muscles fatigue index (\%) - ICC $=0.798$, strong agreement.

During all experimental procedures conducted in hypoxia conditions, $\mathrm{SpO}_{2}$ was $88.4 \pm 3.4 \%$ and in normoxia conditions was $97.1 \pm 0.7 \%$. This demonstrates that there were significant differences between conditions $(\mathrm{p}=0.000$, $\mathrm{d}=3.54$ ). Heart rate was not significantly different between normoxic and hypoxic conditions at the end of the test $(156 \pm 23 \mathrm{bpm}$ and $158 \pm 16 \mathrm{bpm}$, respectively; $\mathrm{p}=0.41$, $\mathrm{d}=0.10)$.

Table 1 presents the isokinetic performance of extensor and flexor muscles at concentric contraction during normoxia and hypoxia conditions. There were no significant differences between isokinetic variables evaluated in both conditions $(\mathrm{p}>0.05)$.

\section{Discussion}

Hypoxia is responsible for a number of physiological adaptations that affect performance (Ortega et al. 2004; Sharp and Bernaudin 2004). However, there is no consensus in the literature on the effects of an acute hypoxic stimulus on the development of muscle torque and muscle fatigue. For this reason, the present study assessed the effects of normoxic and hypoxic conditions on muscular isokinetic torque production and resistance to fatigue. Our main finding was that, although the $\mathrm{SpO}_{2}$ level was lower in the hypoxic condition, the peak torque and total work values did not differ between the two conditions. Our data suggest that muscular isokinetic strength and resistance to fatigue were not influenced by acute hypoxia and support existing evidence that hypoxia has a minimal effect on voluntary force (Amann and Kayser 2009; Perrey and Rupp 2009).

Resistance to fatigue has been shown to be lower during whole body exercise under hypoxemic conditions, however the fatigue mechanism during whole body exercise is complex and multifactorial there is not only a decrease in $\mathrm{SpO}_{2}$, but also an increase in cardiorespiratory requirements. When a small muscle mass is activated, on the other hand, a given absolute force output is exerted and the cardiorespiratory requirements are reduced (Calbet et al. 2009). Thus small muscle mass is a suitable model for investigating the independent effects of $\mathrm{SpO}_{2}$ on muscle fatigue. Our results show no significant difference (normoxia versus hypoxia) in fatigue index related to isokinetic peak torque and total work. This result is comparable with data from other studies showing that $\mathrm{FIO}_{2}$ has little effect on fatigue (Eiken and Tesch 1984; McLellan et al. 1990; Calbet et al. 2003). 
Table 1 Isokinetic muscle performance at concentric contraction in normoxia and hypoxia conditions

\begin{tabular}{|c|c|c|c|c|c|}
\hline Angular velocity (rad/s) & Isokinetic measure & Muscle group & Normoxia & Hypoxia & Effect size (Cohen's d) \\
\hline \multirow[t]{4}{*}{1.05} & Peak torque (Nm) & Extensors & $181.2 \pm 31.5$ & $178.9 \pm 31.8$ & 0.07 \\
\hline & & Flexors & $107.5 \pm 12.6$ & $107.9 \pm 13.4$ & 0.03 \\
\hline & Total work (Joules) & Extensors & $185.3 \pm 33.4$ & $186.7 \pm 38.9$ & 0.04 \\
\hline & & Flexors & $120.9 \pm 19.2$ & $123.3 \pm 25.3$ & 0.10 \\
\hline \multirow[t]{6}{*}{5.23} & Peak torque (Nm) & Extensors & $100.7 \pm 10.8$ & $105.3 \pm 18.3$ & 0.30 \\
\hline & & Flexors & $70.8 \pm 13.2$ & $74.7 \pm 17.1$ & 0.25 \\
\hline & Total work (Joules) & Extensors & $1619.7 \pm 324.5$ & $1696.2 \pm 454.8$ & 0.19 \\
\hline & & Flexors & $941.7 \pm 257.5$ & $948.0 \pm 304.5$ & 0.02 \\
\hline & Fatigue index (\%) & Extensors & $32.3 \pm 31.7$ & $35.8 \pm 12.7$ & 0.15 \\
\hline & & Flexors & $30.93 \pm 35.04$ & $42.13 \pm 13.74$ & 0.42 \\
\hline
\end{tabular}

Data are presented as mean \pm SD.

The fact that muscular strength is not reduced during acute moderate hypoxemia does not therefore confirm previous data (Eiken and Tesch 1984; Badier et al. 1994) nor the hypothesis that hypoxia-induced metabolic disturbance evokes a rise in discharge frequency of group III/IV muscle afferents (Hill et al. 1992) that may affect muscular strength or muscular fatigue through increased inhibitory influence on the central motor drive (Amann and Dempsey 2008; Amann et al. 2009). Previous studies have reported a decreased recruitment of fast-twitch skeletal muscle fibers during the last stage of maximal isokinetic exercise (Gerdle et al. 1989, Casey et al. 1996), thereby suggesting that even during maximal work the exercising muscle becomes increasingly more dependent on the supply of aerobic energy as the exercise proceeds. We would expect impairment in muscular function during isokinetic contraction in the hypoxia condition.

Kawahara et al. (2008), similarly, did not find any difference in muscular fatigue between normoxic and hypoxic situations, and the authors suggested that the low $\mathrm{SpO}_{2}$ in the hypoxic group was compensated by increased blood flow, as they found higher HR during the latter half of the hypoxic exercise. In our study, measured HR did not differ during the isokinetic test. Furthermore, these authors suggested that verbal encouragement given to the experimental volunteers at the start of the exercise may have affected the final outcome. In our study, we also gave verbal encouragement from beginning to end of the isokinetic exercise; this may also have affected the results of the isokinetic evaluation.

A change in the energetics pathways to supply the demand of the exercise may also have contributed to the lack of difference in muscle performance in the hypoxic condition. McLellan et al. (1990) found that a significantly larger increase occurs in the concentration of lactate in the muscle group exercise performed in the hypoxia compared to the normoxia group, suggesting that the inhalation of air with a low oxygen concentration can increase the rate of anaerobic glycolysis. It is possible that the isokinetic exercise performed by subjects during the hypoxic condition is predominantly anaerobic; in other words that the aerobic contribution is negligible.

\section{Conclusions}

Unfortunately, the reasons for the differences between our data and those from previous studies that found a strength and fatigue decrement under hypoxic exercise conditions cannot be fully explained, but we believe that this may be due to our study employing a smaller exercising muscle mass that consumes a smaller amount of oxygen over a short exercise period. The disparity may also be attributable to a difference in the muscle group tested, velocity of muscular action, mode of contraction, the length of exposure to hypoxia, or intensity of hypoxemic stimuli. Collectively, our findings indicate that reduced arterial oxygenation per se has no effect on muscular isokinetic strength of the knee extensors.

\section{Abbreviations}

$\mathrm{FIO}_{2}$ : Fraction of inspired oxygen; HR: Heart rate; ICCs: Intraclass correlation coefficients; MVC: Maximal voluntary contraction; Nm: Newton-meters; $\mathrm{PO}_{2}$ : Oxygen partial pressure; $\mathrm{SpO}_{2}$ : Oxygen saturation.

\section{Competing interests}

The authors declare that they have no competing interests.

\section{Authors' contribution}

RKl: study concept and design; data acquisition, analysis, and interpretation; manuscript preparation and critical revision of the manuscript. FPN and RLV: data analysis, interpretation, manuscript preparation, and critical revision of the manuscript. AABS: data acquisition and critical revision of the manuscript. CABL and MSA: study and conception, manuscript preparation, and critical revision of the manuscript. All authors read and approved the final manuscript.

\section{Acknowledgments}

We would like to thank all subjects who volunteered their time to participate in this study. This study was supported by Financiadora de Estudos e

Projetos (FINEP/Brazil) and Conselho Nacional de Desenvolvimento Científico e Tecnológico (CNPq/Brazil). 


\section{Author details}

'Departamento de Fisiologia, Universidade Federal de São Paulo (UNIFESP), Rua Botucatu, 862, $5^{\circ}$ andar, Ed. Ciências Biomédicas, CEP 04023-062 São Paulo, SP, Brazil. ${ }^{2}$ Centro de Educação Física e Desportos (CEFD), Universidade Federal do Espírito Santo (UFES), Vitória, ES, Brazil. ${ }^{3}$ Escola de Artes, Ciências e Humanidades, Universidade de São Paulo (USP), São Paulo, SP, Brazil. ${ }^{4}$ Setor de Fisiologia Humana e do Exercício, Faculdade de Educação Física e Dança (FEFD), Universidade Federal de Goiás (UFG), Goiânia, GO, Brazil.

\section{Received: 8 August 2014 Accepted: 6 October 2014}

Published: 15 October 2014

\section{References}

Amann M, Dempsey JA (2008) Locomotor muscle fatique modifies central motor drive in healthy humans and imposes a limitation to exercise performance. J Physiol 586:161-173

Amann M, Kayser B (2009) Nervous system function during exercise in hypoxia. High Alt Med Biol 10:149-164

Amann M, Proctor LT, Sebranek JJ, Pegelow DF, Dempsey JA (2009) Opioid-mediated muscle afferents inhibit central motor drive and limit peripheral muscle fatigue development in humans. J Physiol 587:271-283

Badier M, Guillot C, Lagier-Tessonier F, Jammes Y (1994) EMG changes in respiratory and skeletal muscles during isometric contraction under normoxic, hypoxemic or ischemic conditions. Muscle Nerve 17:500-508

Bendahan D, Badier M, Jammes Y, Confort-Gouny S, Salvan AM, Guillot C, Cozzone PJ (1998) Metabolic and myoelectrical effects of acute hypoxaemia during isometric contraction of forearm muscles in humans: a combined 31P-magnetic resonance spectroscopy-surface electromyogram (MRS-EMG) study. Clin Sci 94:279-286

Calbet JA, De Paz JA, Garatachea N, Cabeza de Vaca S, Chavarren J (2003) Anaerobic energy provision does not limit Wingate exercise performance in endurance-trained cyclists. J Appl Physiol 94:668-676

Calbet JA, Radegran G, Boushel R, Saltin B (2009) On the mechanisms that limit oxygen uptake during exercise in acute and chronic hypoxia: role of muscle mass. J Physiol 587:477-490

Caquelard F, Burnet H, Tagliarini F, Cauchy E, Richalet JP, Jammes Y (2000) Effects of prolonged hypobaric hypoxia on human skeletal muscle function and electromyographic events. Clin Sci (Lond) 98:329-337

Casey A, Constantin-Teodosiu D, Howell S, Hultman E, Greenhaff PL (1996) Metabolic response of type I and II muscle fibers during repeated bouts of maximal exercise in humans. Am J Physiol 271:E38-E43

Cohen J (1988) Statistical power analysis for the behavioral sciences. Lawrence Erlbaum Associates, New Jersey

Croisier J-L, Ganteaume S, Binet J, Genty M, Ferret J-M (2008) Strength imbalances and prevention of hamstring injury in professional soccer players. Am J Sports Med 36:1469-1475

Dousset E, Steinberg JG, Balon N, Jammes Y (2001) Effects of acute hypoxemia onforce and surface EMGduring sustained handgrip. Muscle Nerve 24:364-371

Eiken O, Tesch A (1984) Effects of hyperoxia and hypoxia on dynamic and sustained static performance of the human quadriceps muscle. Acta Physiol Scand 122:629-633

Fulco CS, Cymerman A, Muza R, Rock PB, Pandolf KB, Lewis SF (1994) Adductor pollicis muscle fatigue during acute and chronic altitude exposure and return to sea level. J Appl Physiol 77:179-183

Garner SH, Sutton JR, Burse RL, McComas AJ, Cymerman A, Houston CS (1990) Operation Everest II: neuromuscular performance under conditions of extreme simulated altitude. J Appl Physiol 68:1167-1172

Gerdle B, Elert J, Henriksson-Larsén K (1989) Muscular fatique during repeated isokinetic shoulder forward flexions in young females. Eur J Appl Physiol Occup Physiol 58(6):666-673

Hill JM, Pickar JG, Parrish MD, Kaufman MP (1992) Effects of hypoxia on the discharge of group III and IV muscle afferents in cats. J Appl Physiol 73:2524-2529

Kawahara Y, Saito Y, Kashimura K, Muraoka I (2008) Relationship between muscle oxygenation kinetics and the rate of decline in peak torque during isokinetic knee extension in acute hypoxia and normoxia. Int I Sports Med 29:379-383

Kon M, Ikeda T, Homma T, Akimoto T, Suzuki Y, Kawahara T (2010) Effects of acute hypoxia on metabolic and hormonal responses to resistance exercise. Med Sci Sports Exerc 42:1279-1285

McLellan TM, Kavanagh MF, Jacobs I (1990) The effect of hypoxia on performance during $30 \mathrm{~s}$ or $45 \mathrm{~s}$ of supramaximal exercise. Eur J Appl Physiol 60:155-161
Munro BH, Visintainer MA, Page EB (1986) Statistical methods for health care research. JB Lippincott, Philadelphia

Noakes TD, Peltonen JE, Rusko HK (2001) Evidence that a central governor regulates exercise performance during acute hypoxia and hyperoxia. J Exp Biol 204:3225-3234

Orizio C, Esposito F, Veicsteinas A (1994) Effect of acclimatation to high altitude (5050 m) on motor unit activation pattern and muscle performance. J Appl Physiol 77:2840-2844

Ortega VJ, Casal BG, Garrido E, Alcázar B (2004) Neuropsychological functioning associated with high-altitude exposure. Neuropsychol Rev 14:197-224

Perrey S, Rupp T (2009) Altitude-induced changes in muscle contractile properties. High Alt Med Biol 10:175-182

Sharp RF, Bernaudin M (2004) Hif1 and oxygen sensing in the brain. Nat Rev Neurosci 5:437-448

Wehrlin JP, Hallen J (2006) Linear decrease in $\mathrm{VO}_{2}$ max and performance with increasing altitude in endurance athletes. Eur J Appl Physiol 96:404-412

Yeung SS, Suen AMY, Yeung EW (2009) A prospective cohort study of hamstring injuries in competitive sprinters: preseason muscle imbalance as a possible risk factor. Br J Sports Med 43:589-594

doi:10.1186/2193-1801-3-604

Cite this article as: Ivamoto et al:: The influence of acute hypoxic exposure on isokinetic muscle force production. SpringerPlus 2014 3:604

\section{Submit your manuscript to a SpringerOpen ${ }^{\odot}$ journal and benefit from:}

- Convenient online submission

- Rigorous peer review

- Immediate publication on acceptance

- Open access: articles freely available online

- High visibility within the field

- Retaining the copyright to your article

Submit your next manuscript at $\gg$ springeropen.com 